\title{
Communicating Effectively via Tele-oncology (Comskil TeleOnc) : a Guide for Best Practices for Communication Skills in Virtual Cancer Care
}

\author{
Smita C. Banerjee ${ }^{1}$ (D) Jessica M. Staley ${ }^{1} \cdot$ Frances Howell $^{1} \cdot$ Charlotte Malling $^{1} \cdot$ Aimee Moreno $^{1} \cdot$ Chris Kotsen $^{1} \cdot$ \\ Dhwani Parikh ${ }^{2}$ Patricia A. Parker ${ }^{1}$
}

Accepted: 6 January 2021 / Published online: 12 February 2021

(C) American Association for Cancer Education 2021

\begin{abstract}
The emergence of a novel coronavirus (SARS-CoV-2, causing coronavirus disease 2019 or COVID-19) has disrupted the US medical care system. Telemedicine has rapidly emerged as a critical technology enabling health care visits to continue while supporting social distancing to reduce the risk of COVID-19 transmission among patients, families, and clinicians. This model of patient care is being utilized at major cancer centers around the USA — and tele-oncology (telemedicine in oncology) has rapidly become the primary method of providing cancer care. However, most clinicians have little experience and inadequate training in this new form of care delivery. Because many practicing oncology clinicians are not familiar with telemedicine technology and the best practices for virtual communication, we strongly believe that training in this field is essential. Utilizing best practices of communication skills training, this paper presents a brief tele-oncology communication guide (Comskil TeleOnc) to address the timely need to maximize high-quality care to patients with cancer. The goal of the Comskil TeleOnc Guide is to recognize, elicit, and effectively respond to patients' medical needs and concerns while utilizing empathic responses to communicate understanding, alleviate distress, and provide support via videoconferencing. We recommend five strategies to achieve the communication goal outlined above: (1) Establish the clinician-patient relationship/create rapport, (2) set the agenda, (3) respond empathically to emotions, (4) deliver the information, and (5) effectively end the tele-oncology visit. The guide proposed in this paper is not allencompassing and may not be applicable to all health care institutions; however, it provides a practical, patient-centered framework to conduct a tele-oncology visit.
\end{abstract}

Keywords Communication skills training $\cdot$ Coronavirus $\cdot$ Covid-19 $\cdot$ Telehealth $\cdot$ Telemedicine $\cdot$ Tele-oncology

The emergence of a novel coronavirus (SARS-CoV-2, causing coronavirus disease 2019 or COVID-19) has disrupted the US medical care system [1]. Although the use of telemedicine had preceded the COVID-19 pandemic, it has rapidly emerged as an essential technological tool in the current era. Telemedicine enables health care visits to continue effectively while supporting social distancing to reduce the risk of COVID-19 transmission among patients, families, and

Smita C. Banerjee

banerjes@mskcc.org

1 Department of Psychiatry and Behavioral Sciences, Memorial Sloan Kettering Cancer Center, 641 Lexington Ave., 7th Floor, New York, NY 10022, USA

2 Department of Radiation Oncology, Memorial Sloan Kettering Cancer Center, 136 Mountain View Blvd, Basking Ridge, NJ 07920, USA clinicians [2-4]. Telemedicine (or telehealth) is defined by the Health Resources and Services Administration (HRSA) of the US Department of Health and Human Services as "the use of electronic information and telecommunications technologies to support and promote long-distance clinical health care, patient and professional health-related education, and public health and health administration" [5]. Telemedicine technologies include telephone, videoconferencing, internet, store-and-forward imaging, streaming media, and terrestrial and wireless communications [5] with videoconferencing being the most frequently used telemedicine technology [4-6].

As the nations around the world, and in particular the USA, deal with managing patients with COVID-19 and decreasing the spread of infection, telemedicine has become the modality of choice to assist patients with various medical needs, including cancer care. In the last decade, for example, tele-oncology (telemedicine in oncology) has gained traction and found a prominent role in medical, surgical, and radiation oncology, 
as well as in bone marrow transplant and palliative care services [6, 7]. Sabesan [4] describes medical oncology models for tele-oncology services that include face-to-face initial appointments followed by video visits for consultation and supervision of administration of chemotherapeutic agents and oral medication. Additionally, tele-oncology services can benefit clinicians and patients in rural practices, enabling them to have greater access to a cancer center's multidisciplinary team through methods such as virtual tumor group meetings with patient case presentations and discussions [4]. Similarly, teleoncology has found applicability in patient support services such as psychiatry and nutrition counseling [7]. Recently, Memorial Sloan Kettering Cancer Center's Tobacco Treatment Program rapidly scaled up individual and group telehealth treatment visits, showing a higher level of initial patient engagement with telehealth tobacco treatment visits, compared to in-person visits for cancer patients [8]. Until the COVID-19 outbreak, the use of tele-oncology was limited primarily to patients in rural and underserved areas and its use for mainstream oncology care was minimal [6].

Systematic reviews $[9,10]$ assessing effectiveness of tele-oncology have concluded that tele-oncology via videoconferencing is effective for use in the clinical care of oncology patients due to factors such as convenience, reduced travel time and costs, reduced appointment wait times, enhanced access to care, and overall ease of use. However, reports on other patient-reported outcomes have been mixed or non-existent $[9,11-13]$. For instance, patient barriers to engaging in tele-oncology via videoconferencing include difficulty (or reluctance) to communicate with providers using digital platforms such as webcams and videos [13], and the experience of emotional distance between patients and clinicians [12]. Thus, a focus on improving communication, especially when dealing with cancer diagnoses and treatments between clinicians and patients when using tele-oncology, is warranted.

Given the current circumstances, many clinicians have suddenly been faced with tele-oncology care provision without adequate training. Because few practicing oncology clinicians have previously utilized telemedicine technology, training is essential for familiarization with technical components of telemedicine as well as for adjustment to a virtual method of communicating sensitive medical information [6]. A teleconsultation is far more than a simple FaceTime ${ }^{\circledR}$ or Doximity call with a patient, and thus requires some level of training. Providing clinicians with key communication skills specifically for telemedicine is essential to establishing rapport, maximizing engagement, and conducting a comprehensive patient history and virtual exam [14]. This paper addresses this timely and critical need to enhance clinician readiness to provide high-quality care to patients with cancer by presenting a brief tele-oncology communication (Comskil
TeleOnc) guide that utilizes the best practices of an adapted communication skills training [15].

\section{Communicating Effectively via Tele-oncology (Comskil TeleOnc)}

Based on Memorial Sloan Kettering's Comskil Conceptual Model, the Comskil TeleOnc Guide was developed to assist clinicians with limited training in tele-oncology [15]. This conceptual model describes four overarching components that drive the communication interaction between the clinician and patient/families: (i) the communication goal, (ii) communication strategies, (iii) communication skills, and (iv) process tasks. The first component is the communication goal (i.e., the intended outcome of a medical consultation/interaction). The goal is achieved using communication strategies (a priori/ sequential plans that direct communication behavior towards realization of the goal). Strategies, in turn, are achieved with communication goals (discrete verbal utterances) and process tasks (verbal and non-verbal behaviors that create an appropriate environment for effective communication).

While the majority of communication goals, strategies, skills, and process tasks described in this manuscript do not significantly differ from face-to-face clinician-patient consultations, there are some skills/process tasks that are unique to tele-visits (e.g., ensuring privacy, technology check, and make technology back-up plan), whereas others are the same as in face-to-face interactions (e.g., declare agenda, invite agenda, and acknowledge). The sequence of skills recommended and the way in which skill use is exemplified in this manuscript provides a resource for clinicians on effective communication via tele-oncology.

The goal of the Comskil TeleOnc Guide is to recognize, elicit, and effectively respond to patients' medical needs and concerns while utilizing empathic responses to communicate understanding, alleviate distress, and provide support via videoconferencing. Five strategies are recommended for achieving the communication goal and described next (see Table 1 for the Comskil TeleOnc Guide). These strategies include skills and process tasks that should be used throughout the conversation. Examples of each are provided for clarity.

In strategy 1, the clinician establishes the clinician-patient relationship and creates rapport with the patient. The teleoncology visit should begin with a technology check so that the clinician can ensure that the patient can hear and see the clinician well (and vice versa) and enables the patient to appropriately engage in the consultation. This is followed by introductions (if this is the first visit) or greetings (if the visit is a follow-up visit), as needed. It is also important for the clinician to assess patient privacy by confirming that the patient is in a setting where they feel comfortable discussing their private health information. Given the reliance on 
Table 1 A Guide for Communicating Effectively via Tele-Oncology

\begin{tabular}{|c|c|c|}
\hline Skills/process tasks & Description & Examples of what you can say: \\
\hline \multicolumn{3}{|c|}{ Step 1: Establish the Clinician-Patient Relationship/Create Rapport } \\
\hline Technology check & $\begin{array}{l}\text { When first signing on, ensure you and the patient can hear } \\
\text { and see each other well. } \\
\text { If you notice that the patient has a blurry picture and/or } \\
\text { audio problems, you may need to prompt them to hold } \\
\text { their device still, prop it up against a book, or in some } \\
\text { cases, switch rooms to be closer to their WIFI } \\
\text { router/server. }\end{array}$ & $\begin{array}{l}\text { "Can you see and hear me okay?" } \\
\text { "Please prop up your smart phone up against a book, so } \\
\text { the picture doesn't move in and out." } \\
\text { In situations where the visual/audio still isn't working: } \\
\text { "Please move your phone/computer and go to the place } \\
\text { in your home where your Wi-Fi router is for the best } \\
\text { service." }\end{array}$ \\
\hline $\begin{array}{l}\text { Make introductions (if } \\
\text { first meeting) }\end{array}$ & $\begin{array}{l}\text { Introduce yourself with your name and role. Also, confirm } \\
\text { their name and birth date. }\end{array}$ & $\begin{array}{l}\text { "Hi! I'm Dr. Smith, and I'm a medical oncologist. Please } \\
\text { confirm your name, date of birth, and what you prefer to } \\
\text { be called." }\end{array}$ \\
\hline $\begin{array}{l}\text { Greet the patient (if } \\
\text { not the first meeting) }\end{array}$ & Greet the patient appropriately. & "Hi Theresa. How have you been?" \\
\hline Assess patient privacy & $\begin{array}{l}\text { Confirm that your patient is in a setting where they feel } \\
\text { comfortable discussing their private health information. }\end{array}$ & $\begin{array}{l}\text { "Before we get started, I'd like to make sure that you're } \\
\text { in a space where you feel comfortable talking about your } \\
\text { health information." }\end{array}$ \\
\hline $\begin{array}{l}\text { Make technology } \\
\text { back-up plan }\end{array}$ & $\begin{array}{l}\text { Establish a plan for dealing with technology issues before } \\
\text { they arise. }\end{array}$ & $\begin{array}{l}\text { "Can you confirm your phone number? If our video call } \\
\text { stops working, I'll call you on that number." }\end{array}$ \\
\hline $\begin{array}{l}\text { Check patient } \\
\text { preference }\end{array}$ & $\begin{array}{l}\text { Ask if there is someone else they would like to include in } \\
\text { the discussion, including those they live with. If so, invite } \\
\text { them to bring them in so they can be present. If the patient } \\
\text { is using a device other than their phone to engage in the } \\
\text { televisit, you can ask them to call the person and put them } \\
\text { on speaker so they can participate. If others are added to } \\
\text { the visit, make sure to note this in your documentation of } \\
\text { the visit. } \\
\text { If the patient needs or requests an interpreter, the } \\
\text { coordinator can add them in before the televisit begins, or } \\
\text { you can conference them in. }\end{array}$ & $\begin{array}{l}\text { "Would you like to invite anyone else to our televisit } \\
\text { today?" }\end{array}$ \\
\hline $\begin{array}{l}\text { Endorse question } \\
\text { asking }\end{array}$ & $\begin{array}{l}\text { Encourage the patient to stop you if they have questions } \\
\text { and to write down any notes or questions that come up } \\
\text { while you talk. }\end{array}$ & $\begin{array}{l}\text { "If you'd like to take notes, please do so. Also, feel free to } \\
\text { stop me with any questions you have." }\end{array}$ \\
\hline $\begin{array}{l}\text { Make partnership } \\
\text { statements }\end{array}$ & $\begin{array}{l}\text { Partner with the patient and address that though this may } \\
\text { not be the ideal form of communication, you will work } \\
\text { through it together to ensure their questions and concerns } \\
\text { are responded to. }\end{array}$ & $\begin{array}{l}\text { "Thank you for your flexibility to do our visit virtually, } \\
\text { and I'm glad we're able to meet this way. I want to work } \\
\text { together with you as we work through this visit. I'll give } \\
\text { you as much information as you'd like, and feel free to } \\
\text { bring up any questions or concerns you have." }\end{array}$ \\
\hline \multicolumn{3}{|c|}{ Step 2: Set the Agenda } \\
\hline Declare agenda & Discuss what you would like to go over during the visit. & "I'd like to talk about your recent scans today." \\
\hline Invite agenda & $\begin{array}{l}\text { Ask if there are any specific items the patient would like to } \\
\text { go over. }\end{array}$ & "Is there anything else that you'd like to discuss today?" \\
\hline $\begin{array}{l}\text { Set expectations, if } \\
\text { appropriate }\end{array}$ & $\begin{array}{l}\text { For example, you may want to go over how much time is } \\
\text { allotted for the visit, or what can and cannot be covered } \\
\text { during a televisit. }\end{array}$ & $\begin{array}{l}\text { "So, we have about half an hour together today, and I } \\
\text { want to make sure we're able to cover everything you'd } \\
\text { like to talk about." }\end{array}$ \\
\hline
\end{tabular}

technology, it is recommended that the clinician has a technology back-up plan (e.g., telephone number, alternate platform) in mind that ensures a process for dealing with technology issues before they arise. Next, it is helpful to check a patient's preference for people they would like to include in the discussion, including those whom they live with as well as those outside of their home with whom they would like to conference in. Within rapport formation, it is also important for the clinician to endorse question asking during the visit and encourage the patient to pause the conversation if they have questions. Clinicians should also continue to encourage patients to take notes or write down questions that come up during the conversation. Finally, partnership statements (e.g., "we will get through this together" and "we will work together to make this meeting helpful") allow for alliance formation between the clinician and the patient and can provide support.

Strategy 2 involves setting an agenda for the tele-oncology visit. In order to accomplish agenda setting, it is helpful for the clinician to declare their agenda and discuss items to be reviewed during the visit. It is also recommended to invite the patient's agenda and ask if there are any specific items the patient would like to discuss. Additionally, the clinician 
Table 1 (continued)

\begin{tabular}{|c|c|c|}
\hline $\begin{array}{l}\text { Negotiate/Prioritize } \\
\text { agenda }\end{array}$ & $\begin{array}{l}\text { Help the patient prioritize the most important information } \\
\text { they would like to get out of the day's visit. }\end{array}$ & $\begin{array}{l}\text { "In the time we have today, what's the most important } \\
\text { information you'd like to know?" }\end{array}$ \\
\hline $\begin{array}{l}\text { Check patient } \\
\text { understanding }\end{array}$ & $\begin{array}{l}\text { Check the patient's understanding regarding the reasons } \\
\text { for the visit. }\end{array}$ & "So, what's the reason for our visit today?" \\
\hline \multicolumn{3}{|c|}{ Step 3: Respond Empathically to Emotions } \\
\hline Acknowledge & $\begin{array}{l}\text { Pay attention to emotional cues from the patient during } \\
\text { your visit, such as fidgeting, tuning out, crying, or looking } \\
\text { very worried. Verbally acknowledge these cues during the } \\
\text { visit. }\end{array}$ & "You seem to be very anxious today." \\
\hline $\begin{array}{l}\text { Encourage expression } \\
\text { of feelings }\end{array}$ & $\begin{array}{l}\text { Establish that even though you're not meeting in-person, } \\
\text { this is still a safe space where the patient can express their } \\
\text { emotions and concerns. }\end{array}$ & $\begin{array}{l}\text { "I know this isn't the same as meeting in my office, but I } \\
\text { hope you feel comfortable sharing anything. How are } \\
\text { you feeling?" }\end{array}$ \\
\hline Validate & $\begin{array}{l}\text { Make a statement expressing that the patient's emotional } \\
\text { response to an event or an experience is appropriate and } \\
\text { reasonable. }\end{array}$ & "I can imagine how hard this must be for you." \\
\hline Normalize & $\begin{array}{l}\text { Make a comparative statement which expresses that a } \\
\text { particular emotional response is not out of the ordinary. }\end{array}$ & $\begin{array}{l}\text { "It's not unusual to feel so sad at a time like this. Many of } \\
\text { my patients have shared similar feelings." }\end{array}$ \\
\hline Use silence & $\begin{array}{l}\text { Though silence may feel awkward in a televisit, it is still an } \\
\text { important tool to allow patients to process information } \\
\text { effectively and gather their thoughts. } \\
\text { Be mindful that there may be a lag/delay in the } \\
\text { conversation due to tech issues, so it's important to pause } \\
\text { and allow the patient ample time to respond and speak } \\
\text { after delivering information or asking a question. }\end{array}$ & $\begin{array}{l}\text { Pause after speaking and wait a few seconds before } \\
\text { responding to a patient to reduce interruptions. Use } \\
\text { visual cues, such as nodding, to show that you are } \\
\text { listening. }\end{array}$ \\
\hline \multicolumn{3}{|c|}{ Step 4: Deliver the Information } \\
\hline Preview & $\begin{array}{l}\text { Orient your patient to information that you are about to } \\
\text { provide. }\end{array}$ & $\begin{array}{l}\text { "Now, I'll go over some side effects that you may start } \\
\text { experiencing by next week." }\end{array}$ \\
\hline Provide information & $\begin{array}{l}\text { Give information using the KISS (keep it short and simple) } \\
\text { strategy and break up the information into manageable } \\
\text { chunks. }\end{array}$ & $\begin{array}{l}\text { "You may have a mild fever, not more than } 101 \text { degrees. } \\
\text { If higher than that, call my office." }\end{array}$ \\
\hline Check understanding & $\begin{array}{l}\text { Check the patient's understanding of information discussed } \\
\text { so far. }\end{array}$ & $\begin{array}{l}\text { "I know I've given you a lot of information. Can you tell } \\
\text { me, in your own words, what you heard so I can make } \\
\text { sure everything came across clearly?" }\end{array}$ \\
\hline \multicolumn{3}{|c|}{ Step 5: End the televisit } \\
\hline $\begin{array}{l}\text { Time-check, if } \\
\text { appropriate }\end{array}$ & $\begin{array}{l}\text { Provide a time-check } 5-10 \text { minutes before the end of your } \\
\text { visit to set expectations for wrapping up the visit. This will } \\
\text { help you and the patient organize your thoughts, so the } \\
\text { conversation doesn't end too abruptly. }\end{array}$ & $\begin{array}{l}\text { "So, it looks like we have } 10 \text { more minutes before we need } \\
\text { to stop. Let's make sure we go over self-care at home and } \\
\text { when you should call the hospital. How does that sound?" }\end{array}$ \\
\hline Summarize & Go over the main points of your discussion. & $\begin{array}{l}\text { "So, just to review: we discussed what to do if your fever } \\
\text { gets higher, if you feel like you're going to throw up, and } \\
\text { when you should call our office." }\end{array}$ \\
\hline Invite questions & Invite the patient to ask you any questions. & "What questions do you have?" \\
\hline $\begin{array}{l}\text { Endorse question } \\
\text { asking }\end{array}$ & $\begin{array}{l}\text { Encourage the patient to contact you outside of the visit } \\
\text { time if they have any lingering questions. }\end{array}$ & $\begin{array}{l}\text { "Please call my direct number if you think of any } \\
\text { questions after our visit ends." }\end{array}$ \\
\hline $\begin{array}{l}\text { Provide referrals, } \\
\text { when appropriate }\end{array}$ & $\begin{array}{l}\text { Depending on the patient's needs, provide referrals when } \\
\text { appropriate to specialties such as psychiatry, social } \\
\text { work, integrative medicine, palliative care, etc. }\end{array}$ & $\begin{array}{l}\text { "We have many different resources that can address } \\
\text { your personal needs, and we are always open to } \\
\text { discussing those so we can find the best services for } \\
\text { you." }\end{array}$ \\
\hline Review next steps & $\begin{array}{l}\text { Review what will happen following the televisit and close } \\
\text { the consultation. }\end{array}$ & $\begin{array}{l}\text { "Before we end, I just want to make sure we discuss the } \\
\text { next steps. My coordinator will call you to schedule a } \\
\text { visit in } 2 \text { weeks. We will meet virtually, like today. And, if } \\
\text { you start to feel sick, take your temperature and call my } \\
\text { office." }\end{array}$ \\
\hline
\end{tabular}

should set expectations and review how much time is allotted for their visit. If the clinician is not able to address all of their and their patient's agenda items, it is recommended that they negotiate and prioritize items to ensure the patient receives the most important information they need from the day's visit. Finally, checking a patient's current understanding of the reason for the visit can help the clinician structure the conversation and fill in knowledge gaps when appropriate.

Strategy 3 involves empathically responding to the patient's emotion or experience and introduces core skills that should be interspersed throughout the interaction. This strategy includes skills such as acknowledge, validate, normalize, and encourage expression offeelings. These verbal acknowledgments of support 
and care during this difficult time are even more relevant in a post-pandemic world, especially given that in-person interactions are limited and some patients may be forced into more isolated settings with less social support. Though it can be difficult to assess a patient's emotional state via a virtual platform, encouraging patients to verbally express their concerns and feelings is crucial to establishing rapport and trust in the patient-clinician relationship. Appropriate use of silence is also encouraged during a tele-oncology visit. Though silence may feel awkward at times, it is still an important tool to allow patients to process information effectively and gather their thoughts. Clinicians should also be mindful that there may be a lag or delay in the conversation due to technical issues, so it is important to pause and allow patients ample time to respond and speak after delivering information or asking a question.

Strategy 4 includes delivery of the key medical information. This can be accomplished by previewing the information before going into details to help orient the patient and assist in information organization. While the clinician provides information, we recommend using the KISS (keep it short and simple) strategy in addition to breaking up the information into manageable chunks. After provision of information, it is important to, again, check the patient's understanding to ensure there are no misconceptions, misinformation, or misperception about the information discussed in the tele-oncology visit.

Lastly, strategy 5 involves ending the tele-oncology visit. It is recommended that clinicians provide a time-check roughly a few minutes before the end of the visit to set expectations for wrapping up. This will help the clinician and the patient organize their respective thoughts and will prevent an abrupt end to the conversation. After the time-check, it is helpful for the clinician to summarize the main points of the discussion and to invite questions from the patient. Clinicians should also endorse question asking, encouraging patients to contact them outside of the visit and provide contact information, especially if there are any lingering questions. Providing referrals to specialties such as psychiatry, social work, integrative medicine, and palliative care may be helpful for some patients, and the clinician must evaluate that on a case-by-case basis. The visit should end with a clear review of next steps, including what will happen following the tele-visit.

\section{Discussion}

This paper describes a newly developed Comskil TeleOnc Guide, curated by our team of communication experts and practicing oncology clinicians, and refined in partnership with colleagues from Telemedicine, Patient Experience, and other faculty members with substantial experience in providing teleoncology care. Focusing on the utilization of communication skills, adapted from our educational programming based on our Comskil conceptual model, this guide maximizes care provision for patients via videoconferencing. As cancer care centers around the nation advance into an increasingly digital era, it is paramount that clinicians be prepared for conducting effective consultations via videoconferencing. The guide presented here is not all-encompassing or prescriptive, but rather keeps communication best practices in mind to provide a patient-centered framework for conducting a tele-oncology visit. Our aim in developing this communication guide is to provide direction to clinicians on how to more effectively communicate with their patients in a post-pandemic health care system. The long-term objective of the research team is to develop a virtual Comskil TeleOnc Coaching Intervention to improve quality of care related to clinician-patient communication and patient satisfaction in oncology care delivered via tele-oncology.

Acknowledgements The study team would like to thank Dr. Jamie S. Ostroff, Dr. Nessa Coyle, Anna Boyko, Eoin Dawson, Sofia Fatalevich, Jennie Huang, Ruth Manna, and Laura Paloubis for their input on the Comskil TeleOnc Guide.

Funding Research reported in this paper was supported in part by a grant from the National Cancer Institute (P30CA008748; PI: Dr. Craig Thompson).

\section{Declarations}

Disclaimer The content is solely the responsibility of the authors and does not necessarily represent the official views of the NIH.

\section{References}

1. Hick JL, Hanfling D, Wynia MK, Pavia AT (2020) Duty to plan: health care, crisis standards of care, and novel coronavirus SARSCoV-2. NAM Perspectives. Discussion paper. National Academy of Medicine. https://doi.org/10.31478/202003b

2. Calton B, Abedini N, Fratkin M (2020) Telemedicine in the time of coronavirus. J Pain Symptom Manag 60:e12-e14. https://doi.org/ 10.1016/j.jpainsymman.2020.03.019

3. American Telemedicine Association. Covid-19: policy update 3.17.20. https://info.americantelemed.org/covid-19-cms-hhs-deaupdates-3-17-20. Accessed 25 May 2020

4. Sabesan S (2014) Medical models of teleoncology: current status and future directions. Asia Pac J Clin Oncol 10:200-204. https:// doi.org/10.1111/ajco.12225

5. The Office of the National Coordinator for Health Information Technology (ONC). Telemedicine and Telehealth. https://www. healthit.gov/topic/health-it-initiatives/telemedicine-and-telehealth. Accessed 25 May 2020

6. Sirintrapun JS, Lopez AM (2018) Telemedicine in cancer care. Am Soc Clin Oncol Educ Book 38:540-545. https://doi.org/10.1200/ EDBK_200141

7. Satcher RL, Bogler O, Hyle L, Lee A, Simmons A, Williams R, Hawk E, Matin S, Brewster AM (2014) Telemedicine and telesurgery in cancer care: inaugural conference at MD Anderson Cancer Center. J Surg Oncol 10:353-359. https://doi.org/10.1002/ jso. 23652 
8. Kotsen C, Dilip D, Carter-Harris L, O'Brien M, Whitlock CW, de Leon-Sanchez S, Ostroff JS (2020) Rapid scaling up of telehealth treatment for tobacco-dependent cancer patients during the COVID-19 outbreak in New York City. Telemed e-Health 1-10. https://doi.org/10.1089/tmj.2020.0194

9. Cleison K, Zurawel-Balaura L, Wong RKS (2010) How effective is video consultation in clinical oncology? A systematic review. Curr Oncol 17:17-27. https://doi.org/10.3747/co.v17i3.513

10. Larson JL, Rosen AB, Wilson FA (2018) The effect of telehealth interventions on quality of life of cancer patients: a systematic review and meta-analysis. Telemed e-Health 24:397-405. https://doi. org/10.1089/tmj.2017.0112

11. Fergus KD, McLeod DL, Carter W et al (2014) Development and pilot testing of an online intervention to support young couples' coping and adjustment to breast cancer. Eur J Cancer Care 23: 481-492. https://doi.org/10.1111/ecc.12162

12. Coelho JJ, Arnold A, Nayler J, Tischkowitz M, MacKay J (2005) An assessment of the efficacy of cancer genetic counselling using real-time videoconferencing technology (telemedicine) compared to face-to-face consultations. Eur J Cancer 41:2257-2261. https:// doi.org/10.1016/j.ejca.2005.06.020

13. Kruse S, Clemens PK, Shifflett K et al (2018) Evaluating barriers to adopting telemedicine worldwide: a systematic review. J Telemed Telecare 24:4-12. https://doi.org/10.1177/1357633X16674087

14. Yunus F, Gray S, Kevin C. Fox, et al. (2016) The impact of telemedicine in cancer care. J Clin Oncol 27:e20508. https://doi.org/10. 1200/jco.2009.27.15_suppl.e20508

15. Kissane DW, Bylund CL, Smita C. Banerjee, et al. (2012) Communication skills training for oncology professionals. J Clin Oncol 30:1242-1247. https://doi.org/10.1200/JCO.2011.39.6184

Publisher's Note Springer Nature remains neutral with regard to jurisdictional claims in published maps and institutional affiliations. 